Viso - Cadernos de estética aplicada

Revista eletrônica de estética

ISSN 1981-4062

No 11, jan-jun/2012

http://www.revistaviso.com.br/
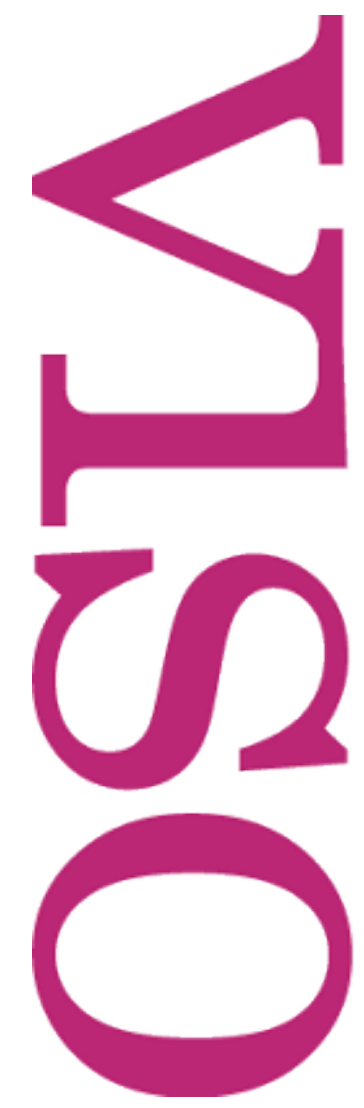

\title{
O formalismo naturalista de Hutcheson
}

\section{Verlaine Freitas}

Universidade Federal de Minas Gerais (UFMG) 


\section{RESUMO}

\section{O formalismo naturalista de Hutcheson}

Nosso objetivo é fazer um breve comentário do texto "Questões de gosto", de Carla Damião, abordando aspectos conceituais mais enfatizados pela autora em sua leitura da estética de Shaftesbury e Hutcheson. A partir dos conceitos de sentido interno e de unidade na variedade, tal como Francis Hutcheson os concebe, procuraremos falar brevemente sobre algumas implicações do formalismo de viés naturalista deste autor para o conceito de gosto.

Palavras-chave: Francis Hutcheson - gosto - formalismo

\section{ABSTRACT}

\section{Hutcheson's Naturalist Formalism}

Our goal is to make a brief comment on the text "Questions of Origin about Taste," by Carla Damião, addressing conceptual aspects more emphasized by the author in her reading of the aesthetics of Shaftesbury and Hutcheson. Taking the concepts of internal sense and unity amidst variety, as Francis Hutcheson conceives of them, we try to talk briefly about some implications of the somewhat naturalistic formalism of this author to the concept of taste.

Keywords: Francis Hutcheson - taste - formalism 


\section{FREITAS, V. "O formalismo naturalista de Hutcheson". In: Viso: Cadernos de estética aplicada, v. VI, n. 11 (jan- jun/2012), pp. 236-243.}

\section{DOI: 10.22409/1981-4062/v11i/137}

Aprovado: 04.09.2012. Publicado: 07.09.2012.

(C) 2012 Verlaine Freitas. Esse documento é distribuído nos termos da licença Creative Commons Atribuição-NãoComercial 4.0 Internacional (CC-BY-NC), que permite, exceto para fins comerciais, copiar e redistribuir o material em qualquer formato ou meio, bem como remixá-lo, transformá-lo ou criar a partir dele, desde que seja dado o devido crédito e indicada a licença sob a qual ele foi originalmente publicado.

Licença: http://creativecommons.org/licenses/by-nc/4.0/deed.pt_BR

Accepted: 04.09.2012. Published: 07.09.2012.

(C) 2012 Verlaine Freitas. This document is distributed under the terms of a Creative Commons Attribution-NonCommercial 4.0 International license (CC-BY-NC) which allows, except for commercial purposes, to copy and redistribute the material in any medium or format and to remix, transform, and build upon the material, provided the original work is properly cited and states its license.

License: http://creativecommons.org/licenses/by-nc/4.0/ 
O texto de Carla Damião possui uma temática altamente relevante e de grande interesse para a reflexão estética, não apenas em termos de pesquisa histórica, mas também para a crítica da sensibilidade contemporânea do fenômeno artístico. Seu foco principal é o conceito de gosto tal como se delineou nos escritos estéticos de dois importantes autores ingleses dos séculos XVII e XVIII, a saber, John Ashley Cooper, o terceiro conde de Shaftesbury, e Francis Hutcheson. A perspectiva geral da autora dirige-se ao conceito de desinteresse como definidor da atitude judicativa perante o fenômeno estético, que se delineia a partir da noção de um sentido interno tomado como algo natural, tornando possível a conexão de várias representações que não são definidas pela ligação direta com os objetos dos sentidos. A primeira parte do texto enfoca alguns elementos da teoria de Shaftesbury, tanto que contrastam com a concepção de Hutcheson, quanto também Ihe dão suporte, sendo apropriados e desenvolvidos por este último. Devido à clareza com que a autora expõe os pontos de sua abordagem, e considerando também nossa maior familiaridade com a estética de Hutcheson, propomos fazer aqui, não um comentário geral do texto, mas sim algumas reflexões sobre o significado de conceitos estéticos deste autor inglês, contidas no texto referido primordialmente por Damião, Investigação sobre a origem de nossas ideias de beleza e virtude.

Embora a autora tenha explicitado, em seu texto originalmente exposto no encontro do Grupo de Trabalho de Estética, a necessidade de não lermos Shaftesbury e Hutcheson apenas como pré-kantianos - posição com a qual concordamos -, alguém já familiarizado com a Crítica da faculdade do juízo fica facilmente impressionado com a enorme importância que tais concepções estéticas têm para quase todos os conceitos da "Analítica do belo", desde a ideia de um comprazimento desinteressado, no primeiro momento, até a de sensus communis, no quarto momento. A própria ideia de um sentido interno, de especial interesse para Damião, é significativa para a epistemologia de Kant, pois tal conceito aparece com muita frequência na Crítica da razão pura, na medida em que é contrastado com o princípio de constituição transcendental do sujeito. No que concerne à importância para a estética, a ênfase na dimensão interna de um sentido é relevante pelo fato de fundar uma esfera judicativa que não é imediatamente deduzida de nossa conexão material com os objetos no mundo.

Tal como salienta a autora do texto que comentamos, Hutcheson distingue três tipos de ideias ou - tal como nos acostumamos a designar a partir da epistemologia de Kant representações: 1) as ligadas diretamente à sensação, 2) as concomitantes ou reflexivas e 3) as de intelecção pura. O sentido da beleza será dito como interno pelo fato de se situar no plano da sensibilidade reflexiva, tal como diz James Shelley ${ }^{1}$, e não da sensação imediata. A percepção do prazer da beleza será dada pelo modo com que somos afetados internamente pela ideia ou representação de uma unidade na variedade nos objetos. A dificuldade, porém, surge já na própria apresentação que Hutcheson faz desse sentido interno, na medida em que, antes de delinear conceitualmente seu espaço próprio na interioridade de nossos poderes cognitivos, precisa advogar sua qualificação como um sentir propriamente. Tal estratégia se torna imperativa pelo modo com que se 
viu obrigado a responder a Hobbes e Mandeville, que advogam a dependência de nosso sentido da beleza para com nossos conceitos de interesse e vantagem, fundados em uma concepção por assim dizer egocêntrica, conectada ao amor-próprio. ${ }^{2}$ Em contraste com isso, Hutcheson quererá dizer do sentido interno como algo imediato e natural, e sua estratégia argumentativa pode nos enganar, pois insiste repetidas vezes na analogia entre o sentido interno e a sensação. Para o autor, em ambos os casos não existe relação de dependência do sentido para com nosso conhecimento da utilidade, proveito ou vantagem - argumento longamente enfatizado por Carla Damião. Tal como expõem claramente Emily Michael e Fred S. Michael, "nós não percebemos a beleza como aprazível porque ela satisfaz um interesse, mas, diferentemente, ela se torna interessante porque é naturalmente experimentada como aprazível". ${ }^{3}$ Esta via argumentativa será reforçada por algo bastante referido por vários comentadores, a saber, a exclusão de conhecimento, educação e exemplo como meios de melhorar nosso senso de beleza, como pode ser visto claramente nesta muito citada passagem:

Este poder superior de percepção é propriamente denominado um sentido por causa de sua afinidade aos outros sentidos, na medida em que o prazer não surge de nenhum conhecimento de princípios, proporções, causas ou da utilidade do objeto; mas sim somos afetados imediatamente com a ideia de beleza; além disso, nem o mais acurado conhecimento aumenta este prazer da beleza, por mais que aquele possa acrescentar um prazer racional distinto a partir das perspectivas de vantagem ou a partir do aumento de saber. ${ }^{4}$

Diante disso, Peter Kivy tomou como um dos elementos mais evidentes na teoria de Hutcheson o que ele chamou de uma concepção não-epistêmica da beleza, em virtude desta negação sistemática do conhecimento, como o que nós chamamos hoje de mediação conceitual para o gosto. ${ }^{5}$ James Shelley, por sua vez, discorda de tal leitura, posto que, para ele, o que estaria em jogo propriamente não seria a exclusão de todo e qualquer conhecimento, mas tão-somente daqueles ligados ao interesse, fundado no amor-próprio e na perspectiva de vantagem, e não de toda e qualquer dimensão conceitual. $O$ autor chega mesmo a inverter a relação entre conceito e beleza em Hutcheson, dizendo que o paradigma do senso de belo seria, não a beleza natural com sua imediatidade, mas sim o teorema, cuja beleza residiria na unidade de infinidades em um único princípio demonstrativo. ${ }^{6}$ Segundo pensamos, esta última leitura é a mais, por assim dizer, progressista, e favorável a Hutcheson como estratégia de sua inserção em um desdobramento histórico da estética como disciplina filosófica. Por outro lado, tal como diz Peter Kivy, não temos, nessa leitura, uma fidelidade àquilo que foi pretendido por Hutcheson em sua formulação original na primeira edição de seu Inquiry, chegando o comentador a dizer que reconhece que o caráter não-epistêmico da estética de Hutcheson é inadequado, errôneo, mas não deixa de ser genial, brilhante, pelo fato de ter aberto o caminho para toda a ciência estética que Ihe sucedeu. ${ }^{7}$

De nosso ponto de vista, cremos que tanto James Shelley quanto Peter Kivy têm razão em suas perspectivas, na medida em que, de acordo com este último, a intenção 
originária de Hutcheson é de fato formalista, no sentido de excluir todas as considerações alheias à conexão quase matemática entre a variedade e a unidade dos objetos ditos belos. Por outro lado, Shelley está correto ao insistir em uma leitura mais favorável do Inquiry, tendo em vista seu expressivo vínculo com a teoria kantiana. Diferente de Peter Kivy, entretanto, bem como da argumentação de James Shelley, dizemos que o equívoco do formalismo de Hutcheson não deve ser apenas taxado como tal, mas também não retirado de cena por uma leitura histórica progressista. Seria necessário percebermos o quanto este próprio formalismo é deveras instrutivo para se conceber nossas relações possíveis com o objeto estético.

Há uma conexão interessante entre o formalismo de Hutcheson e sua insistência na dimensão natural do nosso senso de beleza. Tal como em Kant, a naturalidade de nossos poderes de conhecimento se associa à valorização da necessidade de se abstrair de tudo que é estranho à pureza formal. Isso se dá pelo fato de que toda dimensão de conteúdo da beleza obriga a se considerar sua dimensão histórica, os processos sociais de sua gênese, desenvolvimento e modificações sucessivas ao longo do tempo. Tal como dirá muitos anos mais tarde Theodor Adorno, essa perspectiva inclui também a ideia da mutabilidade das próprias formas, que deixam de ser legíveis apenas em função de um princípio abstrato como o da unidade na variedade e passam a contar como um elemento de conteúdo com direito próprio. Em outras palavras, a necessidade histórica que permeia a mutação das formas é um elemento de conteúdo que leva à consideração de princípios não meramente formais-abstratos para o próprio âmbito formal. ${ }^{8}$

É preciso ter claro, por um lado, que a ideia de unidade na diversidade, naturalmente, tem seu valor, pois aponta para um princípio de articulação dos elementos de uma representação que ilumina muito das produções artísticas ocidentais, bem como parece bastante potente para elucidar o nosso prazer de contemplação das belezas naturais. Por outro lado, ela é extremamente parcial em seu formalismo, devido ao fato de abstrair totalmente o tipo, a natureza, a qualidade, a especificidade desses elementos que são diversamente agrupados em uma unidade. A multiplicidade a ser unificada apresenta discrepâncias muito grandes, não apenas em virtude da diferença do meio em que a ação formativa opera, ou seja, sonoro, visual, de movimento etc., mas mesmo dentro de cada um destes âmbitos, em que há diferenças qualitativas entre os elementos, de tal forma que a excelência de sua articulação é traduzida de forma precária e insuficiente quando é falada apenas através da correlação quase matemática entre um diverso e uma unidade que encontram um ponto ótimo de vinculação. Que um artista inclua apenas elementos suaves em sua composição pictórica ou musical faz exigir certa mestria de unificação qualitativamente diferente de uma proposta que inclua elementos críticos a uma concepção de mundo, ou dissonantes, ou sem sentido, ou sexualmente provocativos etc. O princípio de articulação e de convergência das multiplicidades é tingido pelas cores socialmente visíveis de cada elemento que constitui a obra de arte, de modo que uma pintura pode consistir perfeitamente em apenas um único gesto de 
uma pincelada em uma tela, quando então a beleza deste movimento singular é nutrida pela ousadia com que enfrenta toda uma concepção prévia de produção de valores estéticos que gravitam tradicionalmente ao redor da excelência de aglutinação de múltiplos elementos.

Disso se segue uma consequência relevante para o próprio conceito de gosto, na medida em que não se vincula apenas propriamente ao prazer determinado por uma articulação formal de elementos visíveis, audíveis etc., mas inclui um posicionamento crítico-reflexivo dessa determinação histórico-social dos múltiplos elementos que entram na composição da unidade da obra. Não é contingente que Hutcheson deprecie enfaticamente o exemplo e todo tipo de consideração cultural que interfere e é capaz de formar o gosto, insistindo na dimensão natural dessa faculdade. Este naturalismo do gosto como faculdade é a consequência imediata do formalismo quase matemático da correlação entre a unidade e variedade. A uma ausência de distinção qualitativa dos elementos que constituem a obra deve corresponder uma abstração da diferença histórica da formação da própria capacidade de ajuizamento da obra. O gosto, nesse sentido, fica também formalizado, adstrito a nossa capacidade de perceber a unificação formal de elementos, cuja multiplicidade se dá apenas no âmbito homogêneo de um grau maior ou menor de dispersão. Em contraste com isso, é necessário um esforço conceitual especificamente dirigido para se mostrar o quanto a unidade da obra, que inegavelmente deve sempre existir em um grau minimamente satisfatório, é composta de forma qualitativamente diferenciada, em virtude de seu posicionamento histórico em relação ao modo com que cada época percebe as múltiplas facetas da realidade. Além disso, é preciso considerar, também, a importância culturalmente determinada desse ótimo de equacionamento entre unidade e diversidade, posto que esta concepção por assim dizer aristotélica de um meio-termo entre dois extremos abstrai das circunstâncias históricas específicas em que se pode perfeitamente tomar como mais significativo um desses polos, ou seja, valorizar mais a unidade ou a variedade.

\footnotetext{
* Verlaine Freitas é professor associado do Departamento de Filosofia da UFMG.

1 SHELLEY, J. "Aesthetics and the world at large". In: British Journal of Aesthetics, v. 47, n. 2 (April, 2007), p.182.

${ }^{2}$ Sobre essa necessidade de responder a Hobbes e Mandeville em Hutcheson, cf. MICHAEL, E.; MICHAEL, . S. "Hutcheson's account of beauty as a response to Mandeville". In: History of European Ideas, v. 12, n. 5, 1990.

${ }^{3}$ Idem, p. 663.

${ }^{4}$ HUTCHESON, F. An Inquiry into the Original of Our Ideas of Beauty and Virtue in Two Treatises. Indianapolis: Liberty Fund, 2004, p. 25.

${ }^{5}$ KIVY, P. "The 'Sense' of Beauty and the Sense of 'Art': Hutcheson's Place in the History and Practice of Aesthetics". In: The Journal of Aesthetics and Art Criticism, v. 53, n. 4 (Fall, 1995), p. 350.
} 
${ }^{6}$ SHELLEY, J. Op. cit., pp. 178ss.

${ }^{7}$ KIVY, P. "The perception of beauty in Hutcheson's first inquiry: a response to James Shelley". In: British Journal of Aesthetics, v. 47, n. 4 (October, 2007), p. 430.

${ }^{8}$ Tais considerações sobre o caráter histórico das formas, bem como sobre a dimensão crítica da arte e outras a seguir são evidentemente extemporâneas à concepção de mundo à época de Hutcheson; nossa intenção é apenas extrair algumas consequências da crítica ao formalismo do autor para uma concepção de gosto na leitura atual das obras, a partir de uma possível filosofia da arte de inspiração adorniana. 